\title{
LÍMITES CULTURALES A LA PLENA RECEPCIÓN DEL DERECHO MODERNO EN COLOMBIA. EN TORNO A LOS ORÍGENES COLONIALES DE LA CULTURA DEL INCUMPLIMIENTO ${ }^{1}$ Cultural Limits to the Full Reception of Modern Law in Colombia. Around the Colonial Origins of the Culture of Non-Compliance
}

\author{
Daniel E. Flórez Muñoz $^{2}$
}

Fecha de Recepción: 13 de abril de 2016

Fecha de Aceptación: 20 de mayo de 2016

SUMARIO: 1. Introducción; 2. Economía y sociedad en la Nueva Granada: aproximación al contexto colonial; 3. "La ley se acata pero no se cumple": orígenes de la cultura del incumplimiento de reglas; 4. La independencia: en torno a la Modernidad postergada y los males del antiguo régimen; 5 . Conclusiones; 6 . Referencias bibliográficas

\footnotetext{
${ }^{1}$ El presente artículo es un avance de la investigación titulada Las bases del derecho en Colombia, adscrita al grupo de investigación Filosofía del derecho, derecho internacional y problemas jurídicos contemporáneos, de la Facultad de Derecho y Ciencias Políticas de la Universidad de Cartagena.

2 Docente de la Facultad de Derecho y Ciencias Políticas de la Universidad de Cartagena. Estudiante de la Maestría en Derecho, Universidad de Cartagena. Miembro del Grupo de Investigación en Filosofía del Derecho, Derecho Internacional y Problemas Jurídicos Contemporáneos.
} 


\section{CÓMO SE CITA ESTE ARTícULO (Normas APA-6)}

Flórez Muñoz , Daniel E. (2016). Límites culturales a la plena recepción del derecho moderno en Colombia. En torno a los orígenes coloniales de la cultura del incumplimiento. Revista Jurídica Mario Alario D'Filippo, VIII (16), pág 85-104.

\section{RESUMEN}

El presente trabajo sostiene que la recepción del derecho moderno en Colombia no logró abolir o superar un conjunto de prácticas, relaciones y jerarquías sociales propias de un periodo histórico previo a la Modernidad. Se conserva así un contexto social que en buena medida promueve un tipo de sociedad y de derecho contrario a las bases que fundamentaron el proyecto político liberal y el derecho moderno. En ese orden de ideas, dicha tradición basada en la costumbre constituye un límite empírico al pleno desarrollo de la modernidad jurídica en Colombia. Esta Tradición Pactista de origen colonial, caracterizada por los pactos entre fuerzas equiparables y la interpretación flexible de las normas jurídicas, ha permeado la evolución del Derecho Moderno en Colombia al punto de naturalizar fenómenos como la creciente cultura del incumplimiento de reglas. Esta cultura dificulta las condiciones de posibilidad de una verdadera y plena injerencia de las formas jurídicas en el interior de los procesos de transformación social, creando una frontera entre derecho y sociedad, la cual disminuye considerablemente las garantías que permiten la formación de una cultura democrática en Colombia.

\section{PALABRAS CLAVE}

Tradición pactista, tradición contractual, modernidad, ineficacia.

\section{ABSTRACT}

This paper argues that the reception of modern law in Colombia failed to abolish or overcome a set of practices, relationships and social hierarchies of a historical period prior to Modernity. Thus a social context is preserved which, to a great extent, promotes a type of society and of right contrary to the foundations underlying the liberal political project and modern law. In this vein, this tradition based on custom constitutes an empirical limit to the full development of legal modernity in Colombia. This Pactist Tradition of colonialism, characterized by pacts between comparable forces and the flexible interpretation of legal norms, has permeated the evolution of modern law in Colombia to the point of naturalizing phenomena such as the growing culture of non-compliance with rules. This culture hinders the conditions for the possibility of a true and complete interference of the juridical forms within the processes of social transformation, creating a border between law and society, which considerably diminishes the guarantees that allow the formation of a democratic culture in Colombia.

\section{KEYWORDS}

Pactist Tradition, contractual tradition, modernity, inefficiency. 


\section{INTRODUCCIÓN}

En el presente trabajo pretendo indagar al interior de las bases sobre las cuales en Colombia se construyeron las nociones e instituciones propias del derecho liberal moderno, éste último ejemplificado por excelencia en la ley abstracta y general. En busca de tales construcciones se realizará un contraste directo con el conjunto de estructuras y prácticas de tipo señoriales propias del contexto colonial, las cuales sin lugar a dudas son entendibles en su contexto originario pero injustificables en el actual. El modelo colonial reproduce y naturaliza una forma pre-moderna de entender las prácticas jurídicas, caracterizada entre otras cosas por el poco arraigo de la ley en el ciudadano y la frágil legitimidad institucional, ambas anomalías típicas de nuestros Estados Latinoamericanos (García y Rodríguez, 2003). Dicho límite empírico al desarrollo de la idea moderno-contractual de derecho ha conllevando principalmente a la permanencia de una -ya bastante larga- tradición jurídica pactista basada más en las costumbres de tipo señoriales que en la institucionalidad moderna. La tradición jurídica pactista se encuentra caracterizada precisamente por los recurrentes acuerdos convencionales entre fuerzas que se entienden a sí mismas como equiparables aun cuando una de estas fuerzas la constituya el ente estatal. Estas convenciones suponían un momento originario o inaugural de estipulación de reglas de conductas, quedando de esta forma obviadas todas aquellas garantías que preexistían al momento de la celebración del pacto. Las formas jurídicas quedaban a merced de los constantes y periódicos cambios al interior de las relaciones de poder. Los resultados de lo anterior son la inseguridad jurídica, un modelo hermenéutico que favorece la interpretación acomodaticia y la ineficacia de las normas jurídicas vigentes.

En la realización del presente trabajo se utilizaron fuentes contemporáneas al estudio, identificando a Rubén Jaramillo Vélez y Mauricio García Villegas como los referentes principales. Se expondrá brevemente el contexto al interior del cual se dio lugar al nacimiento de la tradición pactista. Para esto se señalan algunos de los momentos dentro del desarrollo histórico del derecho colombiano en el cual encontramos claramente la permanencia anacrónica de este tipo de tradición que supone en la actualidad un límite concreto a los procesos de modernización y consolidación de una cultura ciudadana de corte democrático. Identificaremos como un elemento particularmente problemático de esta anomalía el fenómeno de la cultura del incumplimiento a la ley, exponiendo algunos de sus principales características e identificando sus distintas formas de expresión social. El estudio de esta temática es relativamente escaso al interior de los círculos jurídicos, siendo de mayor relevancia para historiadores y economistas. En relación a este extraño desinterés de algunos sectores de la academia jurídica, comenta Carlos Santiago Nino: "Es sorprendente que no obstante la visibilidad de la tendencia argentina hacia la ilegalidad [...] ella no haya sido señalada hasta ahora por politólogos, historiadores y economistas como un factor significativo para dar cuenta del subdesarrollo argentino" (Nino, 2005, p. 28. Citado en García, 2009, p. 18) En ese orden de ideas, el profesor Mauricio García 
Villegas, quien es en Colombia la principal autoridad que desde el derecho ha elevado su análisis para contribuir críticamente al entendimiento y superación de estos problemas, comenta, en relación a los estudios de la temática por parte de la academia nacional:

Lo sorprendente es que esta cultura del desacato no haya despertado mayor interés entre los académicos colombianos. Los historiadores hacen referencia frecuentemente a la falta de cumplimiento de las reglas, pero no se detienen a explorar las raíces ni las causas de ese comportamiento. La ciencia política prácticamente se ha desentendido de todo lo que tienen que ver con la eficacia del derecho, a pesar de la importancia insoslayable que ha tenido el discurso jurídico - para bien o para mal- en la construcción de la cultura política nacional. La sociología, por su parte, ha estado más preocupada por comprender la dominación de las clases subalternas que por estudiar comportamientos sociales, temas culturales o institucionales (García, 2009, p.18).

Buena parte de nuestra historia constitucional se nos muestra como la historia de Cartas de Batalla (Valencia Villa, 1987), donde las élites han asumido los textos constitucionales como armas al interior de la contienda política. Sostendremos que son estas mismas élites quienes han impedido o postergado permanentemente el desarrollo pleno de la modernidad en nuestro país, privando al estado colombiano de la posibilidad de hacer frente a sus problemáticas mediante un uso instrumental más que simbólico del derecho ${ }^{3}$ Es entendible, por tanto, la razón por la que los cambios sociales que se intentan realizar únicamente por la vía legal suponen un fracaso prematuro, en virtud que, por hallarse en la capa más superficial de la estructura social, las normas jurídicas son incapaces de modificar o extirpar comportamientos o estructuras políticas muy arraigadas (García, 2006, p. 299; 2009, p. 301; North, 1993) Me encuentro convencido de que solamente superando dichas dificultades anacrónicas se podrá mantener la legitimidad e institucionalidad, condiciones propias de la naturaleza del Estado de derecho, entendido este como organización política que encuentra su fundamento empírico en la democracia (Habermas, 1991) y no en una cultura de pactos entre élites y gamonales (García, 2010; Moncayo, 2004) Únicamente la asunción de las categorías modernas de derecho, individuo y libertad posibilitaría la construcción de una sociedad civil actuante y deliberativa, tan necesaria para la consecución de una verdadera paz, que se manifieste en el respeto del orden jurídico-constitucional y las efectivas garantías sociales para los ciudadanos.

\section{ECONOMÍA Y SOCIEDAD EN LA NUEVA GRANADA: APROXIMACIÓN AL CONTEXTO COLONIAL}

Después de 1492 lo que hoy es Colombia sufría los efectos de la organización económica impuesta por España a la totalidad de sus colonias con la finalidad de retardar su desarrollo económico y de hacer de ellas un mercado para sus productos. En este sentido, estancos,

\footnotetext{
${ }^{3}$ Respecto al uso instrumental y simbólico del derecho, véase la tesis doctoral del profesor García Villegas en la Universidad Católica de Lovaina, publicada por Uniandes en 1993: "La Eficacia Simbólica del Derecho" (1993) Igualmente véase García y Santos, 2004; Rodríguez, 2003; Botero, 2010b, p. 1-86 y Botero, 2003.
} 
alcabalas, resguardos de Indígenas, encomienda, prohibición de la libertad de comercio exterior, fueron una traba poderosa al libre desarrollo de las economías coloniales (Nieto Arteta, 1996, p. 18) Encontramos como primer hecho a resaltar la forma en la que colonias españolas desde sus orígenes fueron vistas y gestadas como un mercado para productos europeos más que como focos de desarrollo en sí mismas. De allí que las instituciones tanto fiscales como económicas creada por España para sus colonias, impidieran su prosperidad, y en ultimas, su auto-sostenibilidad. La dependencia, la deuda y la crisis económicas más que problemas actuales deben ser entendidas como patologías crónicas propias de los procesos de génesis de la Nación.

Pero en estos contextos no solo América gozaba de una débil rentabilidad y solvencia interna. La misma España sufría ya, paralelamente, una muy profunda crisis: al no tener la cultura del ahorro, propia de la mentalidad burguesa ${ }^{4}$, el oro americano, más que el mejor de los activos, se constituyó para España en un grave problema de manejo, en la medida en que la inflación y la inexistencia de Bancos generaba caos y anemia económica al interior del sector agrícola español. Éste sector económico, al lado de los pequeños talleres, eran importantes motores de la economía española (retrógrada con respecto al resto de Europa de la época) Talleres activos como los de Sevilla y Andalucía se vieron duramente afectados por esta imposibilidad de planificación económica derivada del ingreso sin control del oro de las Indias. Al respecto, comenta el profesor David Mercado Pérez, que Carlos V dejó al morir una deuda pública de cinco millones de ducados de oro y Felipe II multiplicó dicha deuda hasta los cien millones de ducados de oro. El déficit de la corona española nunca se pudo sanear y se convirtió así en el de más larga duración en la historia universal (Mercado Pérez, 1998, p. 86) Habría que aclarar que a diferencia de lo que habitualmente se sostiene en relación a la herencia de España en cuanto al modelo económico del Nuevo Mundo-entendido como la prolongación del feudalismo que regía en España en el momento de la conquista ${ }^{5}$ - que en España, en realidad, no hubo un feudalismo pleno y esta particularidad se evidencia, por ejemplo, en el contraste entre la sociedad española y la francesa durante el Medioevo. Se puede establecer que en ésta última efectivamente sí se consolidó dicho modo de producción, mientras que en la sociedad española, durante los ocho siglos que duró la empresa de la Reconquista, en la medida en que paulatinamente fueron repartiendo pequeños y medianos lotes de tierra a los guerreros, se produjo una formación social muy peculiar, que Guillen Martínez caracteriza con la expresión "Hidalguismo" (Jaramillo, 1999, p. 27) En este orden de ideas, en relación al contexto español en el momento de la conquista, se puede afirmar, tal como lo hace Frank Safford en las primeras páginas de su libro El Ideal de lo Practico (1990), que una característica de España en los orígenes de la Modernidad, es decir, en los albores del siglo XVI, fue el que las élites estuvieron dominadas y moldeadas, en contraste con las naciones del norte, por ideales propios de una "cultura militar-

\footnotetext{
${ }^{4}$ Ver al respecto Romero, 1999.

${ }^{5}$ Posición sostenida entre otros por el historiador argentino y profesor de economía Rodolfo Puigross en su célebre obra La España que Conquisto el Nuevo Mundo (1978).
} 
burocrática" pre-moderna (citado en Jaramillo, 1999, p. 33) y, por lo tanto, en mucho más propensa a los fenómenos de autoritarismo y caudillismo como los que más adelante azotaran las realidades políticas propias y de los países conquistados por ésta.

La audiencia de Nueva Granada (actualmente Colombia), elevada a virreinato en el año de 1739, se caracterizó principalmente por mantener una economía de tipo minera antes que agrícola, específicamente productora de oro, dado que la plata desde los inicios representó en su producción un papel secundario a diferencia de los países del Cono Sur, donde esta última fue determinante en la economía interna. Esta economía de base minera se mantuvo aproximadamente hasta la mitad del siglo XVIII cuando la política de los reyes borbones fue encaminada hacia la diversificación de la producción, especialmente en el sector agrícola con el tabaco, algodón, cacao, maderas tintoreras y quinas. Pero a fin de cuenta los resultados no fueron significativos, ya que -comenta Jaime Jaramillo Uribe- solo llegaron a representar el 10\% del comercio de exportación. En ese sentido comenta el profesor Víctor Manuel Moncayo:

El régimen colonial español es sui géneris. Difiere, en primer lugar, del tipo de dominación colonial propio de las sociedades del mundo antiguo. En segundo término no tiene tampoco los rasgos de la hegemonía de los países en transición al capitalismo y donde florece la manufactura, pues los territorios americanos no van a constituirse en el mercado de productos españoles. Es el sistema colonial de un país que a su turno también está sujeto a la dependencia. La particularidad de su colonialismo se deriva de transición al capitalismo y de las cadenas que lo atan a los centros manufactureros, comerciantes y de acumulación de capital dinero; fenómenos estos que van a reflejarse en el comportamiento colonizador frente a los modos de producción y a la fuerza de trabajo existentes en el medio indígena (Moncayo, 1993, p. 175).

Por tanto, a través de todo el siglo XVII y la primera mitad del XVIII, fue el sector minero del occidente granadino el que sostuvo gran parte de la economía colonial. Sin embargo estos mineros y los funcionarios reales constantemente se quejaban de la decadencia de las minas por falta de mano de obra, así como por la carencia de caudales para adquirir nuevos esclavos ${ }^{6}$ (Jaramillo Uribe, 1979, p. 26) Este déficit en mano de obra es entendible si tenemos en cuenta el fuerte proceso de exterminio que hubo en la región colombiana. La población indígena fluctuante en lo que hoy se conoce como territorio colombiano oscilaba entre los 3 y los 4 millones, en contraste con los 25 a 50 millones a los que pudo llegar la población aborigen en territorio mexicano o a los 10 millones que pudo tener lo que fue el Imperio Inca. Esos 3 o 4 millones de indígenas estaban reducidos a poco más de 600.000 hacia los inicios del silgo XVII y más adelante a unos 130.000 al finalizar el siglo XVIII (Jaramillo Uribe, 1979, p. 16) Este hecho (exterminio indígena) resulta en gran medida contradictorio con los extraordinariamente activos procesos de mestizaje.

\footnotetext{
${ }^{6}$ La esclavitud, a pesar de que subsistió hasta 1850, no tuvo gran acogida en la totalidad del territorio colombiano con excepción de algunas regiones en las cuales se adoptó como elemento integrador de la economía. Sin embargo, omitiendo esta excepción, encontramos en la Colombia colonial una fuerte opinión desfavorable hacia esta práctica que conllevó a la suspensión de la introducción de esclavos, derivada de los constantes brotes de resistencia y la fuerte reproducción del denominado cimarronismo.
} 
En relación al aspecto social de la época, eran comunes los procesos para establecer la "limpieza de la sangre" exigida para, entre otras cosas, contraer matrimonio con personas "blancas" así como para detentar ciertos cargos tanto civiles como eclesiásticos. Estos procesos se extendieron hasta las vísperas de la Independencia, cuando por fin fue cuestionada su naturaleza segregaría, pero no se lograron abolir del todo del inconsciente colectivo. Dicho proceso de "limpieza de sangre" era requisito sine qua non para acceder al título de "Don" Para tales efectos la mácula de tener "sangre de la tierra" debía eliminarse con el pago de costosos derechos en la cedula de 1790, "Ilamada eufemísticamente de "gracias al sacar»" (Jaramillo Uribe, 1979, p. 25) Aproximadamente en el año de 1789, Francisco Silvestre publica su Descripción del reino de Santa Fe de Bogotá en el cual calculaba la población de todo el territorio nacional aproximadamente en 826.550 habitantes, que, con base en la categorización socio-racial propia del empadronamiento y extendida a criterios jurídicos, se distribuía de la siguiente forma:

\begin{tabular}{|l|c|}
\hline BLANCOS (Españoles - Criollos) & 277.068 \\
\hline LIBRES (Mestizos) & 368.098 \\
\hline INDIGENA & 136.753 \\
\hline ESCLAVOS & 44.636 \\
\hline
\end{tabular}

(Jaramillo Uribe, 1979, p. 27)

Dicha categorización no era absoluta. Existían a su vez muchos subgrupos ${ }^{7}$, a los cuales también se les reconocían en ciertos círculos de poder algún protagonismo. Lo importante es señalar el alto nivel de mestizaje existente en la Colombia colonial, en contraste con la reducción notable de la población indígena y negra. A modo de conclusión, en el aspecto social vemos como el régimen colonial se configuró como un mecanismo feroz de creación de desigualdades antes que un sistema de unificación en base a una identidad común. Es por esto que el rey, al mejor modo feudal, se sentía soberano de cada uno de sus pueblos más que soberano de uno de ellos. La problemática de la unidad nacional, tan característica e importante en nuestra actual nación, puede rastrearse a estos orígenes. La noción colombiano varia de contenido dependiendo de a quien se le pregunte por su significado. Este tipo de experiencias genera fenómenos tales como el pluralismo jurídico, la ineficacia del derecho y la poca o frágil "identidad nacional".

En relación a la forma de vida individual me parece una particularidad que vale la pena ser resaltada la forma en que se prolonga a lo largo de la historia una especie de Ethos

7 A nivel social, Gerardo Molina (1994) diferencia además de las clases mencionadas en el cuadro, a 3 tipos de Aristocracias diferentes que han impedido históricamente el surgimiento y consolidación del Estado-Nación: 1. Raza (La Plebe, La Canalla y La Vil Multitud), 2. Clero, el cual ocupo y ocupa un papel central en los procesos de corte conservador y retrógrados impidiendo el surgimiento y desarrollo de muchas de las ideas modernas en Colombia, 3. Propiedad Territorial: la cual mantiene unas costumbres señoriales de naturaleza feudal y por tanto contradictorias al modelo liberal de organización político-económico. En conclusión vemos como la Raza, Iglesia y Tierra, son los principales problemas del régimen colonial y son en gran medida responsables del tardío proceso de modernización y unidad del estado Colombiano. 
medieval, propio de un arquetipo de comportamiento muy peculiar, característico, entre otras cosas, de un individualismo de naturaleza pre-moderna y de carácter épico. Quizá esta sea una de las razones que no posibilitó la construcción de una academia ilustrada que permitiera ser luz o construir una puerta de acceso al pensamiento libre y renovador. Quienes tuvieron el privilegio de acceder a la educación superior, quienes pudieron ir a la universidad, lo hicieron con miras a entrar a servir a la corona, haciendo del servicio público el ideal de vida. Este fue uno de los orígenes, según me parece, de una de las conductas más características de la sociedad y la vida pública española e hispanoamericana: la dependencia del puesto público, la vocación burocrática (Jaramillo, 1999, p. 50).

La fuerte influencia de las corrientes más conservadoras del catolicismo español conllevó a la imposibilidad de vivir plenamente una actitud ética específica, eso que Weber bautizará con la expresión de "ascetismo intramundano" (1984, p. 109-184): el control ascético de la vida pulsional con base en el sentido de la responsabilidad individual. Precisamente este Ascetismo intramundano estuvo estrechamente vinculado al proceso de la acumulación originaria del capital y al ascenso de la burguesía como clase catalizadora de transformaciones sociales (Jaramillo, 1999) Por otra parte, mientras que en los países protestantes se venía formando una intelectualidad secular que se pudo proyectar en la actividad científica, la innovación y la ruptura de paradigmas, el intelectual hispánico continuó dependiendo de la Corona y del estamento noble. Inclusive se produjo un cuasiennoblecimiento del letrado: en las Siete Partidas de Alfonso el Sabio, se concedía a los expertos en derecho civil el título de "Caballeros" o "Señor de las Leyes".

Concluiré esta primera parte con una cita de José Manuel Samper en la cual se condensa gran parte de la descripción del régimen colonial:

[E]l gobierno del Virreinato era la representación o encarnación de todo un sistema político, que podía condensarse en estas ideas cardinales: exclusión absoluta de los criollos, de intervención en el gobierno; concentración completa de la autoridad pública conforme a la lógica del despotismo; régimen feudal respecto de la propiedad raíz, los restos de encomienda, las manos muertas, los conventos, la esclavitud y los resguardos de indígenas; intima alianza del Estado y la Iglesia, con absoluta prohibición de otros cultos diferentes al católico; clausura comercial respecto de las producciones no españolas, con el consiguiente monopolio del comercio, y la prohibición de producir en el Virreinato aquellos frutos que pudieran competir con los españoles; régimen de administración de justicia basado en el monopolio de las profesiones forenses, en el secreto de los procedimientos, en el carácter político del poder judicial y en una excesiva y formidable severidad en las penas; régimen fiscal basado en todo linaje de monopolios y restricciones; y en innumerables impuestos, tan vejatorios como mal distribuidos; y, en fin, secuestro intelectual de los pueblos mediante un sistema de instrucción monacal, o muy limitada o calculada de cierto, y la prohibición de libros periódicos que no tuvieran el pase de la autoridad (Citado en Nieto Arteta, 1996, p. 20-21). 


\section{3. "LA LEY SE ACATA PERO NO SE CUMPLE": ORÍGENES DE LA CULTURA DEL INCUMPLIMIENTO DE REGLAS}

Al interior del contexto anteriormente descrito comenzó la gestación de un conjunto de prácticas y de patrones culturales que generarían una tipo de experiencia del derecho moderno por fuera de las condiciones presupuestas por la política liberal y la economía de mercado ${ }^{8}$ Pero no solo las estructuras económicas que sustentaban dicha sociedad estamentaria y jerarquizada se adaptaron casi sin modificación alguna a los novedosos cambios e ideas políticas y jurídicas provenientes de la Europa ilustrada posrevolucionaria. También lo hicieron un buen cúmulo de prácticas propias de la cultura social y política colonial, las cuales, por la permanencia inveterada en el tiempo, son percibidas como naturales o concomitantes a la práctica concreta de lo jurídico y lo político. Como ejemplo de la primera encontramos el incumplimiento de las normas (García, 2009) y un buen ejemplo de la segunda lo constituyen los modelos políticos de corte caudillistas y el uso simbólico del derecho por parte de las autoridades públicas (García y Rodríguez, 2003) En el presente aparte expondremos algunas de las razones por las que es posible rastrear el origen de algunas de este tipo de prácticas a un contexto asociado con valores culturales de tipo pactista originario del periodo de colonial.

La sociedad colonial se encontraba estructurada desde una visión de sociedad orgánica y asociada con los valores culturales y políticos defendidos por el catolicismo contrareformista, visión que era de plano incompatible con las nociones modernas de individuo o de derechos (García, 2005, p. 56; 2006, p. 288; 2009, p. 284) La idea de individuo naciente bajo el espíritu de la Modernidad difiere sustancialmente de las nociones de individuos anteriormente vigentes (cristiana y griega) El individuo moderno ya no es únicamente la existencia temporo-espacial y sensible de un miembro particular de la especie humana. Ahora es mucho más que eso en la medida en que este individuo es entendido como una categoría histórica, provisto de su propia individualidad en cuanto ser humano consciente. El individuo moderno posee el invaluable conocimiento de su propia identidad (Florez, 2010, p. 40) A falta de individuos, en el sentido moderno del término, "había corporaciones que detentaban lo esencial del poder político, moral y económico, pero, sobre todo, había comunidades organizadas en forma de pueblos. El sistema político estaba concebido como un pacto entre el rey y sus pueblos" (García, 2009, p. 285)

Durante la colonia la sociedad era concebida a través de la metáfora organicista: se suponía que el rey, los señores y los vasallos hacían parte de un solo órgano viviente al cual se debían todos. El rey superior a las demás partes pero no superior al todo. Para gobernar, el rey debía ser justo, esto es, debía respetar y mantener los fueros y la autonomía relativa a cada una de las diferentes comunidades cuyo conjunto constituía

\footnotetext{
${ }^{8}$ Un hecho muy diciente de estas anomalías es la forma en que, ante las prohibiciones y crisis española, el contrabando se "institucionaliza" antes del desarrollo y consolidación de un mercado y un comercio estable (Mercado, 1998, p. 80).
} 
la Monarquía (García, 2006: 288). Dicha estructura organicista se materializaba como una apología a las relaciones jerárquicas autoritarias y gremiales, y, por tanto, las prerrogativas y el poder mismo eran fundados en la autoridad sin más por fuera de los causes consensuales y los procedimientos propios de la institucionalidad moderna. De esta forma se hacía de la estructura del poder público -paradójicamente- uno de los principales lastres que impediría vivir satisfactoriamente las expectativas, instituciones y derechos propios de los tiempos modernos, o dicho en otros términos, el Estado permeado por la cultura híbrida entre pactismo e instituciones constituyó un instrumento de límite, por parte de las élites, destinado a movilizar a las colectividades en contra de sus propias posibilidades de emancipación democrática. Lo que pretendemos sostener es que la Tradición Pactista -que en la actualidad también podemos asociar con la cultura del "todo vale", particularmente expresada en las campañas políticas clientelistas, célebres por la compra y venta de votos- aún tan visible en muchos sectores de nuestra cultura jurídico-política, nace, precisamente, en la época colonial derivada de la noción de sistema político imperante en ese entonces. Esta evocaba un pacto entre el rey y sus pueblos a partir del cual cada una de las partes pactantes se comprometía con el respeto de lo que históricamente había sido pactado. En contraste con lo anterior, la idea de Contrato Social en la cual se llega a un acuerdo entre libres para estructurar la comunidad política denominada Estado y de esta forma amplificar libertades y garantizar la seguridad de las mismas a partir de una expresión de la voluntad general, manifestada, abstracta y objetivamente, en lo que denominaríamos Ley ${ }^{9}$ Es esta figura la que constituye la narrativa que soporta la autoridad política moderna, que entra a modificar el respeto a la autoridad derivada del contingente principio de la disposición divina y la mera costumbre. Al interior de dicho sistema político funcionaban los denominados Cabildos que constituían un complejo sistema de representación de tipo corporativa y estructurada jerárquicamente, destinada principalmente a evitar insurrecciones (García, 2006, p. 288; Aninno, 2003, p. 159).

El derecho de la época colonial era la más clara expresión jurídica de un régimen político fundado en la superioridad española y católica sobre la voluntad individual o colectiva de los súbditos americanos (García y Rodríguez, 2003, p. 35) Encontramos como el primero y más importante de sus rasgos el Autoritarismo. Dicho régimen jurídico colonial fue el producto de la incorporación, redefinición y adaptación del denominado derecho metropolitano o derecho español, fuertemente influenciado por la tradición iusnaturalista (García, 2006, p. 285) Los principales documentos de derecho español que llegaron a territorios coloniales fueron: El Ordenamiento de Alcalá (1384), Las Leyes del Toro (1505), Nueva Recopilación de Castilla (1567) y Novísima Recopilación de Castilla (1805) Subordinados a estas se encontraban los fueros o Cartas Municipales y por último estaban las disposiciones propias del derecho Romano y Canónico contenidas en las 7 Partidas de Alfonso X.

9 Al respecto ver Rousseau, 1983. 
Inicialmente en las Indias españolas se aplicaban las normas producidas en el régimen de Castilla. En el año de 1664, Felipe III dispuso que únicamente tendrían vigor las normas redactadas específicamente para las colonias. De esta forma surgen La Recopilación de las Indias (1680) y con estas el inicio de un orden o régimen legal específico para la América Española (García, 2006, p. 288 - 289) Anterior a esta decisión el derecho indiano se aplicaba por subsidiariedad o ausencia de regulación en el derecho metropolitano. Ahora existe todo un corpus destinado a regular las relaciones sociales en la América colonial, sin embargo, en la práctica efectiva prevalecieron los arreglos locales y los criterios derivados de la costumbre como regla de conducta.

El derecho originado en Castilla sólo era una fuente normativa entre otras. Si bien, desde el punto de vista puramente formal se le consideraba superior a las demás leyes, las normas locales emanadas de los virreyes, las audiencias, los gobernadores, los corregidores, los alcaldes y los cabildos, muchas de ellas fundadas en la costumbre y la equidad, comprendían el grueso del derecho aplicado en las Indias y a este se le conoce como derecho indiano criollo. A medida que se desarrollaba el régimen colonial, las fuentes locales del derecho, y en particular la costumbre, fueron ganando terrenos, de tal manera que a finales del siglo XVIII el derecho indiano criollo había adquirido una entidad sustancialmente diferente a la del derecho castellano (García, 2005, p. 55).

El que los jueces pudieran apartarse del criterio oficialmente establecido en /a Recopilación de las Indias (1680) se derivó de la distinción conceptual entre justicia y ley. La justificación esencial del derecho era precisamente la realización de la justicia, sirviendo la ley como un instrumento para este propósito, pero en el caso en que el rey o la autoridad pública considerara que la decisión derivada del texto legal carecía de justicia, se fallaba con base en los criterios que la costumbre imponía. Se condicionaba de esta forma la aplicación del derecho al juicio valorativo o axiológico del operador. Esta práctica supuso un catalizador para el enquistamiento al interior de nuestro contexto cultural del fenómeno de la ineficacia instrumental del derecho oficial frente al conjunto de prácticas autóctonas no oficiales que entrarían a regular efectivamente la vida social. El juez colonial cumplía una función primordial en este esquema pre-positivista. En efecto, en una situación de precariedad del derecho escrito, debida a la novedad de las circunstancias coloniales y a la dispersión e incomunicación extrema entre las poblaciones, las audiencias y demás instancias judiciales cumplían un papel integrador y legitimador de gran importancia. C. H. Haring considera que las audiencias fueron las instituciones más importantes del gobierno español en las Indias, mucho más que sus similares cancillerías en España (1947) A través de la flexibilización de los contenidos jurídicos, las audiencias lograron conciliar la validez hispánica del derecho indiano y el principio de autoridad real con las necesidades y los intereses propios de la sociedad colonial (García, 2005, p. 56).

Dicha situación originaria adquiere su máxima expresión en la famosa frase colonial, refiriéndose a la prelación del derecho oficial: "iSe acata pero no se cumple!" La naturaleza 
de esta expresión implica una postura iusfilosófica determinada frente al problema de lo jurídico, de múltiples implicaciones en distintos niveles. Dicha postura dirige su perspectiva no al problema de las fuentes, ni de la vinculatoriedad del precedente judicial, sino que se dirige directamente a la naturaleza misma del derecho, cuestionando el fundamento de la obligatoriedad de la norma jurídica en sentido estricto, sin entrar a discutir su validez. Este tipo de concepciones tomistas ${ }^{10}$, que reducían la validez de la norma jurídica a los criterios de justicia contenidos en ella, permitieron que el juez de la época tuviera un papel protagónico al interior de dicho esquema, fuertemente marcado por el iusnaturalismo y la ineficacia del derecho proveniente de España:

[E]l atributo de la ineficacia tiene sentido desde una perspectiva estática, a partir de la cual se constata una brecha entre lo prescrito por el derecho producido en España y el derecho aplicado en los territorios coloniales. Desde una visión dinámica, en cambio, la ineficacia ya no aparece tan clara, sobre todo si se tiene en cuenta que lo que había en el mediano y largo plazo era una adaptación y acomodamiento del derecho indiano criollo a la realidad social y política reinante (García, 2005, p. 57).

La idea de pacto entre el rey y sus distintos pueblos fue cuestionada fuertemente, no solo por los valores de la Ilustración y las ideas políticas liberales en la Modernidad, sino también, por las ideas absolutistas de la España de mediados del siglo XVIII, inicialmente provenientes de Francia, las cuales consagraban que el rey no tenía límite alguno al ejercicio de sus plenas facultades y por tanto la idea de un pacto que condicionara su poder quedaba descartada. La recepción en las colonias de las ideas absolutistas que lograron imponerse en España no tuvieron los efectos esperados. La idea de un tirano, no solo encendió los ánimos de los criollos siendo este uno de los antecedentes directos de la Independencia. También afectaba a individuos o sectores que gozaban de varios privilegios al interior de la estructura estamentaria colonial. En este orden de ideas el principal problema que encontraron los presupuestos de la monarquía absoluta en las colonias fue el rechazo pleno de la Iglesia Católica, la cual vio amenazados todos los privilegios, relaciones de poder e influencias que había podido construir a partir de su empresa misional en las América. Este rechazo no fue dirigido únicamente a las ideas absolutistas posrevolucionarias. Tuvo también como objeto el pensamiento libre heredero de la reforma luterana. La contrarreforma en América operó de forma previa que el advenimiento de la reforma misma. La reforma supone un tipo de visión de vida asociada con lo que, ya decíamos, Weber denomina "ascetismo intramundano", el cual posibilita la internalización del sentido de lo normativo, creando el sentimiento de deber. Lo anterior se refleja en el comportamiento ciudadano en detalles tan cotidianos como la puntualidad, el respeto a las exigencias de la convivencia o las leyes de tránsito automotor, es decir, todo lo que en general se corresponde con la conducta civilizada y urbana.

\footnotetext{
${ }^{10}$ Para Tomas de Aquino, en su Suma Teológica (1485), la ley era "Una Ordenación racional al bien común, promulgada por autoridad que tiene a su cargo el cuidado de la comunidad". Este es un ejemplo prototípico de la axiología jurídica iusnaturalista que reduce la naturaleza de la norma jurídica a su subordinación al bien común, su fundamento en razón o en la equidad.
} 
José Gutiérrez (1961) ${ }^{11}$ Ilama la atención sobre el hecho de que en Colombia se utilice con demasiada frecuencia la expresión "me toca" en lugar de "debo", lo que según su interpretación significa que no se asume de frente los deberes sino que se los ve como algo impuesto: como lo que "le toca", casi como un castigo. Esta externalidad de las normas de conducta y convivencia social constituye un criterio de referencia para evaluar las razones que una sociedad o determinado grupo social tiene para obedecer el derecho. También puede ser asociada con la imposibilidad de superación del ethos medieval comprometido con valores católicos reaccionarios, por un ethos moderno de naturaleza en gran medida protestante y promotor del sentido de la existencia vital concreta y la responsabilidad. "Me toca en lugar de debo, implica el sentido de una obligación desprovista de interés propio" (Gutiérrez, 1961, p. 170) En ese sentido más adelante agrega el autor:

Aquello que el modismo -me toca- omite es la pregunta: ¿en gracias de qué te toca? Pues sería comprensible que el dedo que señaló la obligación lo hiciera en razón de un motivo. Y ¿Cuál es el motivo de la mayor parte de esas imposiciones? ¿Acaso un motivo espiritual o ético; acaso un motivo de orden trascendental? (...) Lo curioso es que al colombiano le toca hacer esto o aquello, como una imposición social ante la cual se ve impotente para reaccionar. Y esta concepción del deber como algo desagradable pero ineludible, motivado por la situación social, impide la interiorización de los impulsos al trabajo y a la acción, que son característicos del capitalismo y causa eficiente del progreso material de los pueblos en nuestro mundo contemporáneo (1961, p. 171).

No es extraña la postura asumida por Gabriel García Márquez al afirmar que en los colombianos cohabita "la justicia y la impunidad; somos fanáticos del legalismo, pero llevamos bien despierto en el alma un leguleyo de mano maestra para burlar las leyes sin violarlas o para violarlas sin castigo" (citado en García, 2009, p. 20) Por tal razón, la cultura del incumplimiento no sólo se nos muestra como un anacronismo en la forma en la que experimentamos nuestras relaciones sociales y en concreto nuestras relaciones jurídicas. Ella misma constituye una constante histórica que encuentra su origen primordial al interior de la tradición pactista que se consolidó desde la época de la colonia al interior del tejido social perdurando hasta el día de hoy: «Una prueba (...) del profundo arraigo que siempre ha tenido la cultura del desacato en América Latina es el propio lenguaje popular. Así, por ejemplo, aquí son de uso frecuente expresiones como «hecha la ley, hecha la trampa», "la ley es para los de ruana», u otras más oficiales como «se acata pero no se cumple» (García, 2009, p. 17).

Al interior del contexto anteriormente descrito el derecho lejos de constituir el cimiento de la vida en sociedad constituye una razón más para actuar, la cual, lejos de gozar de una especial prelación, en virtud de la autoridad de la cual emana, se muestra como una razón suplementaria que solo es asumida cuando no existe otro remedio. En conclusión podríamos afirmar que en Colombia las circunstancias en las que actuamos valen más que las reglas que obedecemos.

\footnotetext{
${ }^{11}$ Siquiatra y Psicoanalista colombiano, discípulo de Erich Fromm, que en su obra, Gutiérrez, 1961, se detiene a considerar algunas características de nuestra idiosincrasia.
} 
La concepción jurídica según la cual el derecho escrito positivo es sólo un primer paso en la definición del derecho aplicado ${ }^{12}$, fue creando a través de los siglos una cultura del uso instrumental del derecho, no sólo por parte de los ciudadanos, sino también de los gobernantes. El derecho es así flexibilizado y adaptado para servir a fines privados y públicos. En condiciones de precariedad hegemónica del poder político, como las que caracterizaron a los gobiernos del siglo XIX en casi toda América Latina, esta cultura se alimenta ampliamente de razones ligadas a la ilegitimidad del poder político para obstaculizar los intentos de construcción de un Estado de derecho fundado en una concepción jurídica positivista (García, 2005, p.57).

\section{LA INDEPENDENCIA: EN TORNO A LA MODERNIDAD POSTERGADA Y LOS MALES DEL ANTIGUO RÉGIMEN}

Con el advenimiento de la Independencia de las colonias de España se desarrolla un fuerte proceso de "purificación" de los "males imperiales del antiguo régimen" entre los cuales figuraba el derecho colonial (fundado en las costumbres locales y la idea de pacto). Dicho proceso de "purificación" se realizó mediante la importación y adaptación de teorías e ideas que permitirían un derecho más acorde con el contexto histórico independentista y el espíritu del tiempo que se aproximaba desde la Europa posrevolucionaria. Entre las principales corrientes de renovación encontramos las ideas provenientes de Francia con el proceso de Codificación, el cual llevando equiparando la idea de ley y justicia, permitía superar la distinción imperante entre Lex y Jus. Esta importación vino precedida por su principal instrumento para alcanzar tal finalidad: El Código, tomando como paradigma o modelo a seguir el Código de Napoleón de 1804. Este último tuvo una gran acogida en América Latina, tomando su mejor y más clara encarnación en el Código Civil Chileno realizado por Andrés Bello en el año de 1855. Éste fue recibido en la Colombia federal a través de la Ley 84 del 26 de mayo de 1873, introduciéndose de esta forma una tradición codificadora de fuerte influencia civilista ${ }^{13}$, cuyas implicaciones hasta el día de hoy continuamos percibiendo al interior de nuestra cultura jurídica, especialmente en la disputa por la vinculatoriedad del precedente que supone una discusión frente a la jerarquía misma de las fuentes del derecho colombiano (López, 2006) En relación al proceso codificador resulta importante anotar:

La identificación del derecho con la ley es un legado de la Revolución Francesa y de su influencia en la inspiración del Código de Napoleón de 1804. Los seis primeros artículos del título preliminar de este código contienen todo un paradigma jurídico político que identifica derecho y ley. Tal identificación no es explícita, pero se deduce claramente de la redacción de los artículos, los cuales desarrollan un concepto de derecho que sólo tiene por fuente la

\footnotetext{
${ }^{12}$ Esto se logra luego de un proceso de interpretación, evaluación y adaptación de sus contenidos a las circunstancias específicas en las que se aplican, en unión con la conciencia popular de que dicha interpretación y adaptación se hacía en acuerdo con los interés de la elite política dominante.

${ }^{13}$ Dicha tradición codificadora y civilista trajo consigo nuevos elementos para la enseñanza del derecho tales como los Tratados y Manuales de derecho y pudo haber representado un mayor avance hacia el derecho moderno de haber continuado con tal ímpetu, pero fue hipertrofiada por los dogmatismo y formalismos propios del "positivismo a la colombiana". Al respecto López, 2005 y López, 2004.
} 
ley. Al llegar a España el código de Napoleón choca con una concepción tradicional que no sólo establecía la pluralidad de fuentes jurídicas -legislación, costumbre, jurisprudenciasino que desconocía la existencia de fronteras claras entre religión e interpretación de aquellas fuentes. No obstante, el código civil francés, con su vocación universalista y racional, fue objeto de una recepción entusiasta por parte de juristas simpatizantes del proyecto modernista francés. Sin embargo, este entusiasmo no se ve del todo reflejado en la constitución de Cádiz de 1812, la cual, si bien en algunos de sus apartes parece identificar el derecho con la ley prefiere la adopción de una concepción constitucionalizada de los derechos, idea esta que provenía en parte de la legislación de Haití, en la cual el elemento central no era la ley sino la protección de los derechos individuales y, por supuesto, de la revolución estadounidense de 1776 (García, 2005, p. 58).

Igualmente renovadoras fueron las ideas provenientes de la llustración las cuales perfilaban una idea de hombre y mundo por fuera de los criterios teocéntricos defendidos por el catolicismo imperante. La llustración retomó ideas asociadas con la construcción democrática de la comunidad política y la responsabilidad de construir un contexto que posibilitara la conquista de la libertad e igualdad que la Iglesia condenaba a vivir en lo alto de los cielos. Sin embargo, las costumbres señoriales y la tradición pactista logró filtrarse al interior de este nuevo modelo de política, derecho y sociedad al punto de redefinir buena parte de sus principios rectores y conservar casi sin modificación alguna los mismos privilegios del que gozaban las élites locales antes de la Independencia. Por su parte, los cambios normativos no produjeron el efecto esperado. A partir de la creciente ineficacia y la interpretación acomodaticia por parte de operadores judiciales y la administración misma, la costumbre continuó reclamando su papel de principal fuente de construcción de la cultura jurídica en el periodo independentista y republicano.

En relación al componente político, la recepción de las ideas liberales (democracia y Estado de derecho) encontraron un problema en la falta de experiencia de buena parte de la comunidad en el manejo político y administrativo. Se decidió entonces emular modelos de organización política provenientes de otras latitudes y contextos que al ser incorporadas en condiciones materiales distintas a las que donde originariamente se fueron consolidado, cambiaron sus efectos radicalmente:

[Algunos sectores estimaban que] la interpretación radical de la soberanía popular era inadecuada dadas las condiciones de atraso, marginalidad e inexperiencia política del pueblo y que, en consecuencia, debería crearse un Estado fuerte, una especie de Estado de excepción, que pudiera facilitar la transición hacia una verdadera democracia. La lectura de autores de la llustración con frecuencia sirvió para legitimar un cierto despotismo ilustrado que se justificaba y causaba al mismo tiempo en la ausencia de una modernidad consolidada (García, 2005, p. 60).

Es una época donde la centralidad del debate político se concentra en el tema constitucional, haciendo de buena parte del constitucionalismo republicano una muestra de la permanente disputa entre sectores y grupos políticos por imponer su 
visión de sociedad, democracia y Estado ${ }^{14}$ (Valencia, 1987) En contraste con la historia norteamericana donde las élites locales luchaban por lograr el control del mercado y la producción, en las colonias españoles la ausencia de un mercado consolidado generó una fijación obsesiva por parte de las élites locales, encaminada a la captura del aparato estatal para lograr consolidar sus particulares intereses.

Este nuevo lenguaje-proveniente de la llustración y el Derecho Moderno-no logró desterrar la estructura de poder señorial que operaba en los pueblos, entendidos como la unidad básica de legitimidad política. El concepto de nación tuvo que ser adaptado: ya no estaba constituido por individuos -como lo pensaba Sieyes en Francia- sino por provincias, estados o pueblos. No por El Pueblo, sino por los pueblos, dice Francois Xavier Guerra (Guerra, 2000), o mejor aún, por las élites de los pueblos. Los caudillos locales que surgieron de las guerras de Independencia y las viejas castas señoriales de los pueblos tenían el poder suficiente para imponer una adaptación del lenguaje revolucionario a sus propios intereses. Por eso, más que revoluciones hechas por las clases criollas, dice Antonio Annino (2003, p. 160), la independencia fue una revolución hecha por las comunidades locales (García, 2006, p. 294).

La segunda de las importaciones modernas que permitieron el parcial desarraigo de las prácticas pactistas o costumbristas al interior del derecho colombiano la encontramos en el Constitucionalismo Norteamericano. El constitucionalismo contractual - comenta el profesor García Villegas - si bien consideraba que las constituciones eran fruto de un pacto social, una vez promulgadas se suponía que la dinámica pactista -cumplimiento de deberes y obligaciones entre iguales- se dejaba de lado en beneficio de una ley superior que obligaba a todos y no podía ser cuestionada (García, 2006, 292) Este contractualismo se encontraba en directo contraste con el de tipo pactista, en la medida en que no provenía de un derecho consuetudinario de tipo medieval y, por tanto, tampoco se alimentaba de la constitución mixta fundada principalmente en la ampliamente consolidada potestad unificadora del hegemón político-religioso:

Al inicio de la República hubo un relativo consenso alrededor de la necesidad de adoptar constituciones escritas como punto de partida para la construcción de un sistema republicano [...] La constitución y los códigos impusieron un sistema de normas, valores y comportamientos elaborados bajo el supuesto de su racionalidad y universalidad, lo cual estaba en claro contraste con una realidad social heterogénea y multicultural que difícilmente se acomodaba a tales categorías normativas, empezando por la existencia de barreras lingüísticas que impedían a la población indígena, muchas veces mayoritaria, acatar lo dispuesto por una élite gobernante criolla y citadina (García, 2006, p. 292-293).

A pesar de la existencia de los anacronismos hasta ahora expuestos se continuó con la evolución jurídica rumbo hacia la modernidad, postergando la asunción de soluciones

\footnotetext{
${ }^{14}$ En Colombia la principal autoridad en el estudio del constitucionalismo provincial es el profesor Andrés Botero Bernal, quien tomando el rigor de la disciplina histórica se aproxima al análisis del desarrollo o evolución del derecho en Colombia. Al respecto ver: Botero, 2003; 2010a; 2010b.
} 
radicales a los problemas estructurales que limitan una plena experiencia de lo jurídico y lo político en nuestros contextos. En buena medida esta desatención ha sido promovida por algunas élites que entienden la permanencia de este tipo de anacronismos como una condición necesaria para la garantía efectiva de sus lugares jerárquicos y beneficios al interior del tejido social, el sector económico y las prácticas políticas. Por lo tanto, a pesar de continuar el decurso de la historia, las transformaciones se desarrollaron de forma paralela a la consolidación de estos patrones culturales.

Es precisamente la permanencia de la tradición pactista la que posibilita la creciente necesidad que tenían los próceres de la Independencia de ver y utilizar el derecho de naturaleza contractual, solamente como una herramienta para la construcción de la nación y de la ciudadanía. La ausencia de una participación políticamente organizada, ejemplificada clásicamente en la estructuración de partidos políticos de arraigo social, determinó desde nuestros comienzos republicanos el considerable y peligroso traslado del discurso político al discurso jurídico, concretamente al constitucional, como encargado per se de desempeñar la función política de articulación social, tarea propia del sistema político. Dicha hipercentralidad del tema constitucional en el debate político sigue gestándose entre nosotros en la actualidad (García y Rodríguez, 2003, p. 28) y ha degenerado en fenómenos deplorables como los son el reformismo constitucional y el constitucionalismo populista o democracia plebiscitaria.

\section{CONCLUSIONES}

A pesar de los intentos por superar los patrones denominados males imperiales del antiguo régimen, muchos de los elementos propios de la colonia nunca pudieron ser superados a cabalidad por parte de la Tradición Codificadora y el Constitucionalismo contractual. Dichos males continuaban gestándose subrepticiamente, ahora al interior del nuevo régimen bajo otros rótulos o etiquetas, pero defendiendo los mismos intereses y manteniendo las mismas estructuras de tipo colonial.

La incapacidad del derecho republicano para permear el tejido social, lo cual, entre otras cosas, no era un fenómeno nuevo frente al derecho colonial (García y Rodríguez, 2003 , p. 29) se proyecta en la historia hasta la actualidad, determinando buena parte de las formas en las que se relacionan los ciudadanos con las normas jurídicas. La política seguía siendo más importante que la ley general. Se consideraba que "un pueblo siempre tenía derecho a revisar, retomar y mudar su constitución". Cuando una de las facciones políticas conseguía destronar a su rival a través de la guerra promulgaba una constitución con la estructura y el ropaje de un código superior -separación de poderes, derechos, libertades, control del poder, etc- pero que funcionaba como un pacto que podía ser roto cuando una de las partes -la facción opuesta- estimaba que la sociedad o el cuerpo político estaba en peligro de disolución (García, 2006, p. 294). 
Esa es la razón por la que las manifestaciones populares, apoyando o rechazando determinada decisión o situación, expresando su opinión a partir de peticiones, proclamaciones o actas, resultaban de mayor fuerza vinculante a la administración que la ley o la constitución misma. El soberano sólo actuaba legítimamente cuando contaba con el pasional apoyo de las multitudes en plazas y provincias. Esta forma de entender la administración y el derecho generaron las raíces para el fenómeno político protagonizado por el "caudillo"15 el cual más tarde fue denominado "cacique-electoral", protagonistas por antonomasia de los regímenes populistas o democracias clientelistas. Las disputas por el poder electoral que significaba el poder político, e inclusive el poder constitucional, degeneraron en un cúmulo de guerras civiles que, a diferencia de Europa, no terminaron en la consolidación de un poder nacional, sino que fortalecieron los poderíos locales y a las comunidades ya por sí fragmentadas, al tiempo que generaron un especie de cultura de rebeldía y bandolerismo de la cual hoy seguimos sufriendo sus consecuencias.

Cada uno de los episodios de nuestra historia de guerras generaba por lo general una constitución nueva, es decir, una redefinición constante y periódica del contrato originario e imposición de nuevos términos político-operacionales en cuanto a la distribución de cuotas burocráticas y poderíos locales. No resulta extraño, por lo tanto, que en el siglo XIX Colombia haya adoptado 15 constituciones nacionales $^{16}$, dado que el poder constitucional dependía de la voluntad del soberano o facción de turno, siempre y cuando éste contara con la posibilidad instrumental de manipular las pasiones populares. De esta forma, más que un candidato, se convirtió en una figura pseudo-mesiánica, lo que facilitó el sintomático comportamiento pre-moderno de ver al líder político como un tipo Monarca-Dios, propio de los inicios de la Edad Media; un enviado a hacer justicia y redimir a los oprimidos que ciegamente le sigan. Es en este contexto y bajo dichas dificultades genealógicas que se ha consolidado nuestro proyecto de democracia liberal.

La forma en la que el derecho moderno se ha vivido en nuestra historia es diametralmente distinta a las proyecciones e ideales con base en los cuales fue pensado. La fórmula del constitucionalismo contractualista, o liberal, según la cual las partes en conflicto se someten a unas reglas de juegos constitucionales que no pueden ser puestas en tela de juicio a partir de la percepción de injusticia, tuvo poco valor durante el siglo XIX. Se consideraba que el derecho debía ser justo, o de lo contrario no era derecho. Este maximalismo iusnaturalista debilitó la institucionalidad y supeditó el derecho a la política y a la guerra (García, 2006, p. 298-299)Dicha lucha de facciones políticas denominadas pomposamente "partidos políticos" desembocó en una peligrosa fragilidad institucional en la medida en que el poder legítimo provenía primero de las armas antes que del derecho mismo.

\footnotetext{
${ }^{15}$ Para Lynch el caudillo era un jefe regional que derivaba su poder del control que tenía sobre los recursos locales, especialmente las haciendas, lo que le otorgaba acceso a hombres y provisiones. El caudillismo clásico adoptaba la forma de bandas armadas regidas por relaciones patrón-cliente, unidos por los lazos personales de dominio y sumisión y por el deseo común de obtener riqueza mediante el uso de las armas (García y Rodríguez, 2003, p. 31).

${ }^{16} 2$ durante la guerra de independencia (1810 - 1819), 5 durante la Gran Colombia (1819 - 1930), 4 en la nueva granada (1830 1858), 3 durante la Federación (1858 - 1886) y una originada en la regeneración (1886 - 1903).
} 
Una agenda verdaderamente progresista debe partir de una lectura de contexto. Debe asumir el compromiso y responsabilidad que supone la toma de partido al interior de los siempre difíciles procesos de identificación y superación del anacronismo que de una u otra forma han consolidado, no sólo el modelo de sociedad en que vivimos, sino también el tipo de ser humano que somos.

\section{REFERENCIAS BIBLIOGRÁFICAS}

Alfonso, R. D. C., \& de la Historia, R. A. (1807). Las siete partidas del rey don Alfonso el Sabio. Madrid, España: Imprenta Real.

Aninno, A. (2003). Soberanías en lucha. En Antonio Annino y Francois Xavier Guerra (Coords.) Inventando la nación. Iberoamérica Siglo XIX. México: Fondo de Cultura Económica.

Botero, A. (2003). Diagnostico de la Eficacia del Derecho y otros ensayos. Medellín, Colombia: Señal Editorial y Fondo Editorial Biogénesis.

- (2010a). Modelo de lectura del constitucionalismo provincial hispanoamericano. Medellín, Colombia: Universidad de Medellín.

. (2010b). Ensayos Jurídicos sobre Teoría del Derecho. Buenos Aires, Argentina: Editorial la Ley.

Congreso de Colombia. (26 de mayo de 1873). Código Civil Colombiano [Ley 84 de 1873].

Flórez, D. (2009). Tradición Pactista y Derecho Moderno en Colombia. Revista Telemática de Filosofía del Derecho (12), 301-327.

. (2010). En torno a los Orígenes de la Ley y la Sumisión Colectiva Revista Jurídicas 1 (7).

García, M. (2006). Tradición Pactista y Ley de Justicia y Paz Revista Pensamiento Jurídico (17). (2009). Normas de Papel. Bogotá, Colombia: Siglo del Hombre Editores. (2010). El Estado Alterado. Bogotá, Colombia: Dejusticia.

García Villegas, M. (1993). La eficacia simbólica del derecho. Examen de situaciones colombianas (Tesis) Uniandes, Facultad Derecho de la Universidad de los Andes, Bogotá.

García y Rodríguez, C. (2003). (Ed.) Derecho y Sociedad en América Latina. Bogotá, Colombia: ILSA. 
Gutiérrez, J. (1961). De la Pseudoaristocracia a la Autenticidad. Psicología Social Colombiana. México: Editorial Laura.

Habermas, J. (1991). Facticidad y Validez. Madrid, España: Trotta.

Jaramillo Uribe, J. (1979). Etapas y Sentido de la Historia en Colombia. En: Arrubla, M., et al. (Ed.) Colombia Hoy, 4a ed. Bogotá, Colombia: Siglo XXI editores.

Jaramillo, R. (1999). Colombia: La Modernidad Postergada. Bogotá, Colombia: Argumentos. López, D. (2006). El Derecho de los Jueces. Bogotá, Colombia: Legis.

Mercado, D. (1998). La Paz en Colombia, Marco Histórico, Político y Jurídico Revista Jurídica (12).

Moncayo, V. (1993). España y el Régimen Colonial. Revista Politeia (12). (2004). El Leviatán Derrotado. Bogotá ,Colombia: Norma.

Nieto Arteta, L. (1996). Economía y Cultura en la historia de Colombia. 8a edición. Bogotá, Colombia: Ancora Editores.

North (1993). Instituciones, Cambio Institucional y Desempeño Económico. México: Fondo de Cultura Económica.

Puiggrós, R. (1978). La España que conquistó el nuevo mundo. Bogotá, Colombia: Ancora editores.

Romero, F. (1999). Latinoamérica: las ciudades y las ideas. Medellín, Colombia: Universidad de Antioquia.

Rousseau, J. (1983). El Contrato Social. Madrid, España: Editorial SARPRE.

Safford, F. (1989). El Ideal de lo Practico. Bogotá, Colombia: Editorial Ancora.

SANTO TOMÁS, D. A. (2001). Suma teológica. Edición dirigida por los Regentes de Estudios de las Provincias Dominicanas en España. Madrid, España: BAC, 5, 725-731.

Silvestre, F. (1927). Descripción del reino de Santa fe de Bogotá. Completar cita.

Valencia, H. (1987). Cartas de Batalla. Bogotá, Colombia: Editorial Panamericana.

Weber, M. (1984). La Ética protestante como Espíritu del Capitalismo. Madrid, España: SARPRE. 